\title{
Development and Validation of a Cross-Cultural Heart Failure-Specific Quality of Life Questionnaire
}

${ }^{*}$ Nor F. Mohamed, ${ }^{1}$ Siti R. Ghazali, ${ }^{2}$ Nor A. Yaacob, ${ }^{3}$ Aizai A. A. Rahim, ${ }^{4}$ Oteh Maskon ${ }^{5}$

$$
\begin{gathered}
\text { التطوير والتحقق من صحة استبيان نوعية الحياة عبر الثقافات الحاص بالفشل القلبي }
\end{gathered}
$$

$$
\text { نور فردوس محمد، سيتي رودزه غزالي، نور عزواني يعقوب، إيزيا عزان عبدالرحيم، أوتيه مسكون }
$$

ABSTRAC T: Objectives: Heart failure (HF) is a common clinical syndrome with an enormous impact on prognosis and lifestyle. Accordingly, rehabilitation measures need to be patient-specific and consider various sociocultural factors so as to improve the patient's quality of life (QOL). This study aimed to develop and validate a HF-specific QOL (HFQOL) questionnaire within a multicultural setting. Methods: This study took place at the National Heart Institute and Universiti Kebangsaan Malaysia Medical Centre, Kuala Lumpur, Malaysia, between March 2013 and March 2014. A self-administered 75-item HFQOL questionnaire was designed and administrated to 164 multi-ethnic Malaysian HF patients. Exploratory factor analysis was performed to assess the instrument's construct validity. Cronbach's alpha coefficients were used to determine internal consistency. Results: A total of 33 out of 75 items were retained in the final tool. The HFQOL questionnaire had three common factors-psychological, physical-social and spiritual wellbeing - resulting in a cumulative percentage of total variance of $44.3 \%$. The factor loading ranges were $0.450-0.718$ for psychological wellbeing (12 items), 0.394-0.740 for physical-social wellbeing ( 14 items) and $0.449-0.727$ for spiritual wellbeing (seven items). The overall Cronbach's alpha coefficient of the questionnaire was 0.82 , with coefficients of $0.86,0.88$ and 0.79 for the psychological, physical-social and spiritual wellbeing subdomains, respectively. Conclusion: The HFQOL questionnaire was found to be a valid and reliable measure of QOL among Malaysian HF patients from various ethnic groups. Such tools may facilitate cardiac care management planning among multi-ethnic patients with HF.

Keywords: Heart Failure; Quality of Life; Culturally Competent Care; Ethnic Groups; Questionnaire Design; Reliability and Validity; Malaysia.

الملخص: الههف: فشل القلب هو متلازمة سريرية شائعة ذات تأثير هائل على التكهن وأنماط الحياة. ويناءُ على ذلك، يجب أنس أن تكون

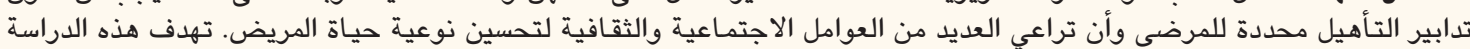

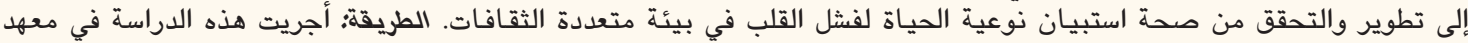

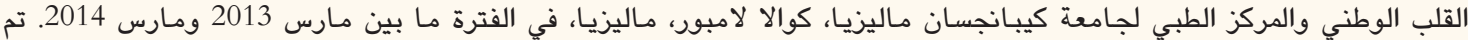

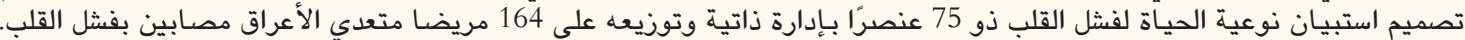

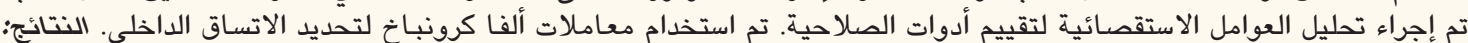

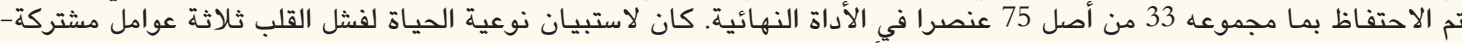

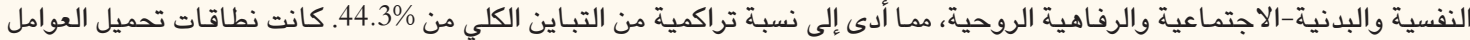

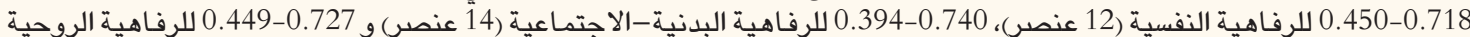

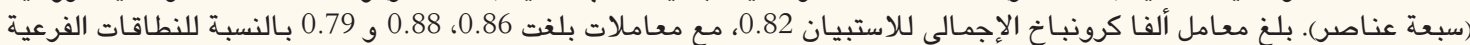

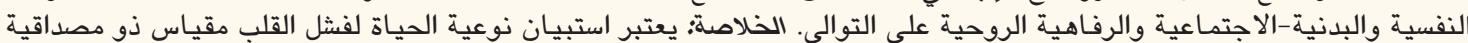

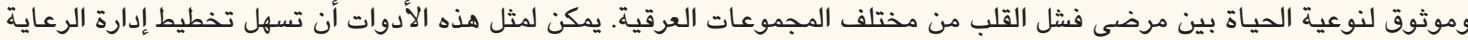

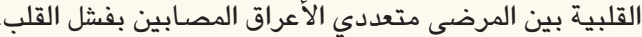

الكلمات المفتاحية؛ فشل القلب؛ نوعية الحياة؛ ثقافة الرعاية المتخصصة؛ فئات عرقية؛ تصميم الاستبيان؛ الموثوقية والهصداقية؛ ماليزيا.

\section{ADVANCES IN KNOWLEDGE}

This study provides a valid and reliable heart failure (HF)-specific questionnaire to measure quality of life (QOL) in a multi-ethnic population.

\section{Application to Patient Care}

The HF-specific QOL questionnaire can be used to assess the QOL of Malaysian HF patients, regardless of ethnic, cultural or religious background.

Such instruments facilitate patient-specific management by prioritising items with a lower QOL domain, enhancing the effectiveness of care as well as patient satisfaction. 
$\mathrm{T}$ He number of heart fallure (HF) Patients worldwide is increasing, with the condition affecting an estimated 26 million people globally. ${ }^{1}$ In Southeast Asia, the population is growing, with the majority younger than 65 years old; however, rapid epidemiological transition has led to high rates of premature death from noncommunicable diseases, particularly cardiovascular disease. ${ }^{2}$ Southeast Asians also have a high prevalence of HF risk factors, including hypertension, tobacco smoking, physical inactivity, overweight/obesity and raised blood glucose levels. Moreover, Southeast Asian patients with $\mathrm{HF}$ tend to be younger and have more severe clinical features, with higher rates of mechanical ventilation and longer hospital stays compared to those in developed countries. ${ }^{2}$ In Malaysia, ischaemic heart disease is a major cause of death, with the condition contributing to $13.2 \%$ of all deaths in $2016 .{ }^{3}$ Unfortunately, as Malaysia has an ageing population, the prevalence and burden of $\mathrm{HF}$ is expected to increase in the future. ${ }^{4}$

Among patients with HF, quality of life (QOL) is not only affected by the physical symptoms of illness but also by a myriad of social, emotional, sexual and mental factors. ${ }^{5}$ In particular, patients may suffer from significant psychological distress due to changes in functional level, work status and family relationships. ${ }^{5}$ As such, the treatment goal in HF is not only to enhance survival rates, but to improve the patient's QOL (i.e. meaningful survival). ${ }^{6,7}$ However, most existing QOL measures for HF patients are based on expert opinions, with only a limited number based on actual patient experiences. ${ }^{8-11}$ Dunderdale et al. opined that QOL measures based on expert opinions rather than on patients' perceptions might demonstrate lower accuracy and usefulness in real-life settings. ${ }^{10}$

Furthermore, QOL may vary in the context of the patient's unique culture and value systems and in relation to their specific goals, expectations, standards and concerns. ${ }^{6}$ Yusuf et al. recommended that cultural and ethnic differences be taken into consideration when designing QOL tools, especially in view of the collectivist nature of Southeast Asian communities. ${ }^{12}$ Recently, efforts have been made to maintain cultural sensitivity when developing QOL measures. ${ }^{13}$ This study therefore aimed to develop and validate a HF-specific QOL (HFQOL) questionnaire within a multi-ethnic setting in Malaysia.

\section{Methods}

This study was conducted at the National Heart Institute (IJN) and Universiti Kebangsaan Malaysia Medical Centre (UKMMC), Kuala Lumpur, Malaysia between March 2013 and March 2014. A preliminary version of the HFQOL questionnaire was developed based on qual- itative findings from in-depth interviews conducted with 19 HF patients. During the interviews, the questions focused on the patients' experiences during HF and the recovery stage; interview guides were developed based on a literature review and feedback from experts in cardiology management. Qualitative data from the interviews were then analysed to identify themes for the questionnaire constructs. ${ }^{14}$ The preliminary constructs were physical wellbeing (i.e. restrictions in physical function), social wellbeing (i.e. dependency on social support networks), psychological wellbeing (i.e. the grieving process and negative emotions regarding adapting to the condition) and spiritual wellbeing (i.e. a personal or religious belief system).

Subsequently, the content of the preliminary HFQOL questionnaire was reviewed by seven experienced professionals, including four cardiologists and three cardiac unit nurses, all of whom had experience managing HF patients of various ethnicities. Each reviewer was asked to rate the relevance of each item for the purposes of the tool from 1-10. They were also asked to evaluate each item's agreement with the identified constructs, which resulted in the rephrasing of some items. The final version of the HFQOL questionnaire was administered in either Malay or English, according to the respondent's preference, and consisted of 75 items scored on a four-point Likert scale, with specific definitions tailored to each item [Table 1]. ${ }^{15}$ All of the reviewers rated the final version of the questionnaire to be relevant and adequate to measure the QOL of HF patients. A pilot study of $35 \mathrm{HF}$ patients confirmed the appropriateness of the questionnaire from a patient's point of view. The questionnaire could be completed by the respondents either individually or with assistance from the researchers in 20 minutes.

A minimum sample of 210 patients was deemed necessary based on the sample size calculations, wherein the construct with the highest number of variables (35 variables) was multiplied by five at $80 \%$ power. ${ }^{16}$ Due to the limited number of patients with HF, a convenience sampling technique was employed to recruit participants. All respondents were either in- or outpatients at the IJN and UKMMC and had HF as identified by cardiologists based on the criteria of reduced left ventricular function (ejection fraction of $\leq 45 \%$ ). ${ }^{17}$ Patients from all three major ethnic groups in Malaysia were eligible to participate in the study; however, only those able to communicate in either Malay or English were included. Patients were assessed by cardiologists for HF severity according to the classifications of the New York Heart Association (NYHA), with class I indicating no HF symptoms and no limitations in ordinary physical activity, class II indicating mild HF symptoms and slight limitations during ordinary activity, class III 
Table 1: Example of items in each construct in a cross-cultural heart failure-specific quality of life questionnaire Item

\begin{tabular}{|c|c|c|c|c|}
\hline Item & \multicolumn{4}{|c|}{ Likert score } \\
\hline \multicolumn{5}{|l|}{ Psychological wellbeing } \\
\hline $\begin{array}{l}\text { I feel sad whenever thinking about my } \\
\text { health condition }\end{array}$ & $\begin{array}{l}\text { Almost every day } \\
\text { of the week }\end{array}$ & $\begin{array}{l}\text { At least } 4-6 \text { days } \\
\text { per week }\end{array}$ & $\begin{array}{l}\text { At least } 1-3 \text { days } \\
\text { per week }\end{array}$ & Never \\
\hline \multicolumn{5}{|l|}{ Physical wellbeing } \\
\hline Ease of breathing & $\begin{array}{l}\text { Difficult even } \\
\text { without performing } \\
\text { any activity }\end{array}$ & $\begin{array}{l}\text { Difficult even } \\
\text { when performing } \\
\text { simple activities }\end{array}$ & $\begin{array}{c}\text { Easy when } \\
\text { performing } \\
\text { simple activities }\end{array}$ & $\begin{array}{c}\text { Easy when } \\
\text { performing any } \\
\text { activity }\end{array}$ \\
\hline \multicolumn{5}{|l|}{ Social wellbeing } \\
\hline Interactions with family members or friends & Very distant & Distant & $\begin{array}{l}\text { The same as } \\
\text { before }\end{array}$ & Strengthened \\
\hline Support from family members & Not supportive & $\begin{array}{l}\text { Less supportive } \\
\text { than before }\end{array}$ & $\begin{array}{l}\text { More supportive } \\
\text { than before }\end{array}$ & Very supportive \\
\hline \multicolumn{5}{|l|}{ Spiritual wellbeing } \\
\hline $\begin{array}{l}\text { Level of spiritual beliefs when having heart } \\
\text { problems }\end{array}$ & None & Reduced & $\begin{array}{l}\text { The same as } \\
\text { before }\end{array}$ & Strengthened \\
\hline
\end{tabular}

indicating significant limitations in activity due to HF symptoms and class IV indicating severe limitations and HF symptoms which persist even at rest. ${ }^{18}$

All quantitative data were analysed using the Statistical Package for the Social Sciences (SPSS), Version 19.0 (IBM Corp., Armonk, New York, USA). Item-level descriptions were performed to explore the distribution of responses. An exploratory factor analysis (EFA) was performed to assess construct validity using a principal component analysis with varimax rotation. The KaiserMeyer-Olkin (KMO) measure of sampling adequacy and Bartlett's test of sphericity was used to assess the adequacy of the sample size for the EFA. ${ }^{19}$ Scree plots and Eigen values of $>1$ were used to guide the number of factors, along with the construct of four domains. ${ }^{20} \mathrm{~A}$ correlation coefficient of $\geq 0.3$ with a $P$ value of $\leq 0.050$ was considered statistically significant. Following the EFA, a reliability analysis was done to assess internal consistency utilising Cronbach's alpha coefficient for each identified factor, with a coefficient of $>0.70$ considered acceptable. ${ }^{21,22}$

The protocols of this study were approved by the IJN Ethics Committee (\#IJNEC/03/2011) and UKMMC Ethics Committee (\#FF-390-2011). Informed consent was obtained from all patients following screening by a cardiologist to determine their fitness to participate in the study.

\section{Results}

A total of 164 HF patients participated in the study, with a mean age of 61 years. The majority of patients were Malay (64\%), male (68.3\%) and married (81.1\%). Many participants were unemployed (37.2\%) and had not been educated past secondary school level (77.4\%). In terms of religious beliefs, the majority were Muslims (65.9\%), followed by Buddhists (16.5\%), Hindus (12.2\%), Christians (4.3\%) and atheists (1.2\%). More than half of the respondents had a family history of heart disease (52.4\%) and were currently non-smokers (90.8\%). Most patients were categorised as having NYHA classes I or II HF (92.1\%), with only two patients (1.2\%) having class IV HF [Table 2].

The KMO measure was 0.81 , with significant sphericity $(P=0.001)$, thus indicating that the sample size was suitable for the EFA. In total, 42 items were eliminated from the HFQOL questionnaire based on poor communality, inter-item correlations and factor loading. The rotated component matrix of the remaining 33 items was loaded into three rather than four common factors, due to the combination of the physical and social wellbeing constructs into a single subdomain. The first common factor, psychological wellbeing, consisted of 12 items with a factor loading range of $0.450-0.718$. The second common factor was physical-social wellbeing 
Table 2: Sociodemographic and clinical characteristics of multi-ethnic Malaysian patients with heart failure $(\mathrm{N}=164)$

\begin{tabular}{|c|c|}
\hline Characteristic & n (\%) \\
\hline \multicolumn{2}{|l|}{ Gender } \\
\hline Male & $112(68.3)$ \\
\hline Female & $52(31.7)$ \\
\hline \multicolumn{2}{|l|}{ Ethnicity } \\
\hline Malay & $105(64)$ \\
\hline Chinese & $33(20.1)$ \\
\hline Indian & $26(15.9)$ \\
\hline \multicolumn{2}{|l|}{ Religion } \\
\hline Muslim & $108(65.9)$ \\
\hline Buddhist & $27(16.5)$ \\
\hline Hindu & $20(12.2)$ \\
\hline Christian & $7(4.3)$ \\
\hline Atheist & $2(1.2)$ \\
\hline \multicolumn{2}{|l|}{ Marital status } \\
\hline Single & $31(18.9)$ \\
\hline Married & $133(81.1)$ \\
\hline \multicolumn{2}{|l|}{ Education level } \\
\hline None & $12(7.3)$ \\
\hline Primary school & $51(31.1)$ \\
\hline Secondary school & $64(39)$ \\
\hline Diploma/college/university & $37(22.6)$ \\
\hline \multicolumn{2}{|l|}{ Employment status } \\
\hline Employed & $57(34.8)$ \\
\hline Unemployed & $61(37.2)$ \\
\hline Retired & $46(28)$ \\
\hline \multicolumn{2}{|l|}{ Smoking status } \\
\hline Non-smoker & $104(63.4)$ \\
\hline Ex-smoker & $45(27.4)$ \\
\hline Current smoker & $15(9.1)$ \\
\hline \multicolumn{2}{|l|}{ Family history of heart disease } \\
\hline Yes & $86(52.4)$ \\
\hline No & $78(47.6)$ \\
\hline \multicolumn{2}{|l|}{ NYHA class } \\
\hline I & $67(40.9)$ \\
\hline II & $84 .(51.2)$ \\
\hline III & $11(6.7)$ \\
\hline IV & $2(1.2)$ \\
\hline
\end{tabular}

NYHA $=$ New York Heart Association
Table 3: Factor loading* of items in a cross-cultural heart failurespecific quality of life questionnaire

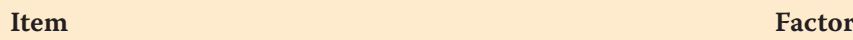

loading

Psychological wellbeing

1. I feel sad whenever I think about my health condition

0.718

2. I feel anxious whenever I think about my health condition

0.702

3. I feel pressured whenever I think about my health condition

0.695

4. I worry whenever I think about my health condition

0.692

5. I feel depressed whenever I think about my health condition

0.660

6. My mind is troubled whenever I think about my health condition

7. I easily feel frustrated

0.630

0.619

8. I feel something is not right with my physical abilities 0.605

9. I feel inferior 0.548

10. I blame myself for the effects of my past lifestyle choices $\quad 0.485$

11. I feel angry whenever I think about my physical weaknesses $\quad 0.480$

12. I often cry

0.450

Physical-social wellbeing

13. Ability to climb up stairs $\quad 0.740$

14. My family responsibilities have increased 0.672

15. Ability to walk 0.654

16. Ability to bend down $\quad 0.647$

17. The effects of my heart problem on my health $\quad 0.621$

18. Interactions with family members or friends 0.587

19. Ease of breathing 0.565

20. Level of tiredness 0.555

21. Quality of sleep 0.538

22. Ability to perform simple exercises 0.516

23. I feel less energetic than I have in the past 0.504

24. My heart problem causes a burden $\quad 0.493$

25. My recent lifestyle is far better than before $\quad 0.481$

26. Appetite 0.394

Spiritual wellbeing

27. Involvement in spirituality is important to me 0.727

28. My spirituality is helpful in facing my heart problem 0.725

29. Level of spiritual beliefs when having heart problems 0.673

30. During disasters, I increase my level of worship/prayer 0.603

31. The concept of life and death is decided by God 0.542

32. Involvement in spiritual activities feels peaceful 0.476

33. During disasters, I believe God protects me from danger $\quad 0.449$

"Using principal axis factoring in which all items with a factor loading of $>0.2$ were removed from the table. 
Table 4: Internal consistency of a cross-cultural heart failure-specific quality of life questionnaire

\begin{tabular}{lcc|} 
Subdomain & $\begin{array}{c}\text { Number } \\
\text { of items }\end{array}$ & $\begin{array}{c}\text { Cronbach's alpha } \\
\text { coefficient }\end{array}$ \\
\hline Psychological wellbeing & 12 & 0.86 \\
Physical-social wellbeing & 14 & 0.88 \\
Spiritual wellbeing & 7 & 0.79 \\
Total & 33 & $\mathbf{0 . 8 2}$
\end{tabular}

and consisted of 14 items with a factor loading range of 0.394-0.740. Lastly, the third common factor, spiritual wellbeing, consisted of seven items with a factor loading range of $0.449-0.727$ [Table 3].

The cumulative percentage of total variance explained by the three common factors was adequate at $44.3 \%$, with a factor-structure coefficient of $39 \%$. In terms of internal consistency, the first two factors (psychological and physical-social wellbeing) had Cronbach's alpha coefficients of $>0.80$, whereas factor three (spiritual wellbeing) had a value of 0.79 . The overall Cronbach's alpha coefficient for the HFQOL instrument was 0.82 [Table 4].

\section{Discussion}

The current study aimed to design and validate a HFQOL questionnaire in a multi-ethnic population in Malaysia. The preliminary version of the questionnaire was designed based on the qualitative findings of in-depth interviews conducted with HF patients which sought to determine their perspectives on QOL. The four constructs identified from these interviews included physical wellbeing (i.e. restricted functionality), social wellbeing (i.e. dependency on social support), psychological wellbeing (i.e. the emotional processes involved in adapting to their illness) and spiritual wellbeing (i.e. religious belief systems). The overall HFQOL and each of its three subdomains were found to be a reliable measure of QOL among Malaysian HF patients, regardless of differences in ethnicity, social background or religious beliefs.

In the current study, the physical and social wellbeing constructs were later grouped into a single subdomain; this may reflect the idea that physical restrictions are closely related to dependency on social support. Moreover, certain physical disabilities can be observed by others, thus affecting how a patient is treated and how that individual interacts in society. ${ }^{23}$ In Malaysia, there is a strong culture of collectivism; as such, patients rely heavily on their family and caregivers for support. ${ }^{24}$ Therefore, Malaysian HF patients who receive social support may perceive themselves to have a better QOL and improved self-care behaviours. ${ }^{25}$ On the other hand, negative perceptions of physical-social interactions may lead to negative psychological responses. ${ }^{26}$

Psychological wellbeing remained a separate subdomain in the final HFQOL questionnaire, thus highlighting the importance of the psychological impact of HF in determining the QOL of affected patients. Patients with HF may suffer negative psychological effects such as sadness, depression, anger and anxiety - all of which were established in the qualitative phase of the current study-due to functional disability, rehospitalisation and daily variations in symptoms, such as dyspnoea and the need for oxygen therapy. ${ }^{7}$ Among other factors, the presence of a close protective individual may strengthen the patient's coping skills, leading to fewer psychological problems. ${ }^{14,27}$

Similarly, spiritual wellbeing also remained a separate subdomain in the final HFQOL questionnaire. This finding is interesting as it indicates that the participants considered spirituality to be a significant part of QOL, despite the multi-ethnic nature of the sample and consequent variations in social norms or religious beliefs. Spiritual peace has been shown to be closely related to mortality risk in HF patients; moreover, reduced spirituality has been associated with decreased psychological and physical wellbeing, thus indirectly contributing to less favourable outcomes as a whole. ${ }^{28}$ According to previous research, spiritual factors related to religious beliefs and practices have enabled patients with advanced HF to cope positively with the disease, improving their psychological wellbeing. ${ }^{29-31}$

This study was subject to certain limitations. First, as the patients were recruited from a tertiary referral hospital, the sample may not be representative of the entire HF population in Malaysia. However, the high proportion of Malay patients included in the current study is reflective of the overall demographic structure of the national population. ${ }^{32}$ The larger number of male patients also conforms to previous research indicating that heart disease is more prevalent in males. ${ }^{33}$ Second, most of the patients had less severe forms of HF as it was deemed unethical to ask severely ill patients to answer research questions that might remind them of their disabilities. This limitation also serves to explain the smaller than ideal sample size. Further research is therefore needed to assess the sensitivity of the HFQOL instrument for patients with different stages of HF. Third, the expert panel strongly recommended that two additional items-sexual relationships and interest in having a life partner-be included in the questionnaire; however, these items were excluded as these concepts did not arise during the interviews. This may be due to general reluctance to discuss such topics or conservative cultural or social norms. Alternatively, this may reflect perceptions that 
such factors are not important aspects of QOL for those suffering from HF, especially for those with more severe disease. Nevertheless, these factors should not be ignored in a care management plan.

\section{Conclusion}

The HFQOL questionnaire is a valid and reliable tool for measuring QOL among multi-ethnic Malaysian HF patients. Such tools may help cardiac and rehabilitation teams to develop patient-specific management plans.

\section{CONFLICT OF INTEREST}

The authors declare no conflicts of interest.

\section{FUNDING}

This study was funded by the Malaysian Ministry of Higher Learning (RAGS \#2013-0012-105-72).

\section{References}

1. Ambrosy AP, Fonarow GC, Butler J, Chioncel O, Greene SJ, Vaduganathan $\mathrm{M}$, et al. The global health and economic burden of hospitalizations for heart failure: Lessons learned from hospitalized heart failure registries. I Am Coll Cardiol 2014; 63:1123-33. https://doi.org/10.1016/j.jacc.2013.11.053.

2. Lam CS. Heart failure in Southeast Asia: Facts and numbers. ESC Heart Fail 2015; 2:46-9. https://doi.org/10.1002/ehf2.12036.

3. Department of Statistics Malaysia. Press release: Statistics on causes of death, Malaysia, 2017. From: www.dosm.gov.my/v $1 /$ index.php? $r=$ column/pdfPrev\&id $=$ Y3psYUI2VjU0 ZzRhZU1kcVFMMThGUT09 Accessed Jul 2018.

4. Rajadurai J, Chew D, Samion H, Pasamanickam K, Yusoff MR, Mohammad NM, et al. Malaysian CPG for heart failure. ASEAN Heart J 2014; 22:66-72. https://doi.org/10.7603/s40602-014-0012-2.

5. Cully JA, Jimenez DE, Ledoux TA, Deswal A. Recognition and treatment of depression and anxiety symptoms in heart failure. Prim Care Companion J Clin Psychiatry 2009; 11:103-9. https://doi.org/10.4088/PCC.08m00700.

6. Adebayo SO, Olunuga TO, Durodola A, Ogah OS. Quality of life in heart failure: A review. Niger J Cardiol 2017; 14:1-8. https://doi.org/10.4103/0189-7969.201914.

7. Nieminen MS, Dickstein K, Fonseca C, Serrano JM, Parissis J, Fedele F, et al. The patient perspective: Quality of life in advanced heart failure with frequent hospitalisations. Int J Cardiol 2015; 191:256-64. https://doi.org/10.1016/j.ijcard.2015.04.235.

8. Rector TS, Cohn JN. Assessment of patient outcome with the Minnesota Living with Heart Failure questionnaire: Reliability and validity during a randomized, double-blind, placebo-controlled trial of pimobendan - Pimobendan Multicenter Research Group. Am Heart J 1992; 124:1017-25. https://doi.org/10.1016 /0002-8703(92)90986-6.

9. Green CP, Porter CB, Bresnahan DR, Spertus JA. Development and evaluation of the Kansas City Cardiomyopathy Questionnaire: A new health status measure for heart failure. J Am Coll Cardiol 2000; 35:1245-55. https://doi.org/10.1016/S0735-1097 (00)00531-3

10. Dunderdale K, Thompson DR, Miles JN, Beer SF, Furze G. Quality-of-life measurement in chronic heart failure: Do we take account of the patient perspective? Eur J Heart Fail 2005; 7:572-82. https://doi.org/10.1016/j.ejheart.2004.06.006.
11. Dunderdale K, Thompson DR, Beer SF, Furze G, Miles JN. Development and validation of a patient-centered health-related quality-of-life measure: The chronic heart failure assessment tool. J Cardiovasc Nurs 2008; 23:364-70. https://doi.org/10.1097/01. JCN.0000317439.82704.e8

12. Yusuf S, Reddy S, Ounpuu S, Anand S. Global burden of cardiovascular diseases: Part II - Variations in cardiovascular disease by specific ethnic groups and geographic regions and prevention strategies. Circulation 2001; 104:2855-64. https://doi.org/10.11 61/hc4701.099488.

13. Lua PL, Salek S, Finlay I. The Malay McGill Quality of Life Questionnaire (MMQOL): Adaptation and validation. Selangor, Malaysia: University Publication Center, 2006. Pp. 5-7.

14. Mohamed NF, Azan A, Lebar O, Shaharom MH, Peterson RF. Family support, positive thinking and spirituality correlates on psychologically distressed heart failure patients. Procedia Soc Behav Sci 2014; 127:484-8. https://doi.org/10.1016/j. sbspro.2014.03.295.

15. Jackson CJ, Furnham A. Designing and Analysing Questionnaires and Surveys: A manual for health professionals and administrators. London, UK: Whurr Publishers, 2000. Pp. 137-80.

16. Gorsuch RL. Exploratory factor analysis: Its role in item analysis. J Pers Assess 1997; 68:532-60. https://doi.org/10.1207/s15327 752jpa6803_5

17. Ministry of Health Malaysia. Management of heart failure: 3rd edition clinical practice guideline 2014. From: www.acadmed. org.my/view_file.cfm?fileid=684 Accessed: Jul 2018.

18. American Heart Association. Classes of heart failure. From: www.heart.org/en/health-topics/heart-failure/what-is-heartfailure/classes-of-heart-failure Accessed: Jul 2018.

19. Worthington RL, Whittaker TA. Scale development research: A content analysis and recommendations for best practices. Couns Psychol 2006; 34:806-38. https://doi.org/10.1177/0011 000006288127

20. Fayers PM, Hand DJ. Factor analysis, causal indicators and quality of life. Qual Life Res 1997; 6:139-50.

21. Costello AB, Osborne JW. Best practices in exploratory factor analysis: Four recommendations for getting the most from your analysis. Pract Assess Res Eval 2005; 10:1-9.

22. Bland JM, Altman DG. Cronbach's alpha. BMJ 1997; 314:572. https://doi.org/10.1136/bmj.314.7080.572.

23. Siegrist J, Junge A. Conceptual and methodological problems in research on the quality of life in clinical medicine. Soc Sci Med 1989; 29:463-8. https://doi.org/10.1016/0277-9536(89)90295-5.

24. Yasin S, Chan CK, Reidpath DD, Allotey P. Contextualizing chronicity: A perspective from Malaysia. Global Health 2012; 8:4. https://doi.org/10.1186/1744-8603-8-4.

25. Gallagher R, Luttik ML, Jaarsma T. Social support and self-care in heart failure. J Cardiovasc Nurs 2011; 26:439-45. https://doi. org/10.1097/JCN.0b013e31820984e1.

26. Rector TS. A conceptual model of quality of life in relation to heart failure. J Card Fail 2005; 11:173-6. https://doi. org/10.1016/j.cardfail.2004.09.002.

27. Jaarsma T, Johansson P, Agren S, Strömberg A. Quality of life and symptoms of depression in advanced heart failure patients and their partners. Curr Opin Support Palliat Care 2010; 4:233-7. https://doi.org/10.1097/SPC.0b013e328340744d.

28. Park CL, Aldwin CM, Choun S, George L, Suresh DP, Bliss D. Spiritual peace predicts 5-year mortality in congestive heart failure patients. Health Psychol 2016; 35:203-10. https://doi. org $/ 10.1037 /$ hea0000271

29. Dunn KS, Horgas AL. The prevalence of prayer as a spiritual self-care modality in elders. J Holist Nurs 2000; 18:337-51. https://doi.org/10.1177/089801010001800405. 
30. Westlake C, Dracup K. Role of spirituality in adjustment of patients with advanced heart failure. Prog Cardiovasc Nurs 2001; 16:119-25. https://doi.org/10.1111/j.0889-7204.2001.00592.x.

31. Bekelman DB, Dy SM, Becker DM, Wittstein IS, Hendricks DE, Yamashita TE, et al. Spiritual well-being and depression in patients with heart failure. J Gen Intern Med 2007; 22:470-7. https://doi.org/10.1007/s11606-006-0044-9.
32. Liu JH, Lawrence B, Ward C, Abraham S. Social representations of history in Malaysia and Singapore: On the relationship between national and ethnic identity. Asian J Soc Psychol 2002; 5:3-20. https://doi.org/10.1111/1467-839x.00091.

33. Savarese G, Lund LH. Global public health burden of heart failure. Card Fail Rev 2017; 3:7-11. https://doi.org/10.15420/ cfr.2016:25:2. 